\title{
Multiplicação e enraizamento in vitro de Minirosa ${ }^{1}$
}

\author{
Multiplication and in vitro rooting of the China Rose
}

\author{
Josefa Diva Nogueira Diniz ${ }^{2 *}$, Jacqueline Leite Almeida ${ }^{3}$, Alexandre Bosco de Oliveira ${ }^{3}$ e Francisco Ronaldo \\ Vidal $^{4}$
}

\begin{abstract}
RESUMO - O trabalho teve como objetivo desenvolver uma metodologia para a micropropagação da minirosa. Foram realizados dois experimentos utilizando explantes retirados de plantas mantidas in vitro. No primeiro experimento, para multiplicação, os explantes foram inoculados em meio MS com BAP, CIN e TCT isoladamente, nas concentrações de 0,$00 ; 0,01 ; 0,10 ; 1,00$ e $10,00 \mathrm{mg} \mathrm{L}^{-1} \mathrm{com} 15$ tratamentos e 20 explantes por tratamento. Verificou-se aos 80 dias, que o BAP na concentração de $1,0 \mathrm{mg} \mathrm{L}^{-1}$ favoreceu a emissão de gemas e o maior peso fresco dos explantes. Para o enraizamento, foram utilizadas diferentes concentrações da formulação dos sais macronutrientes do meio MS (25; 50; 75 e $100 \%$ ) combinado com diferentes concentrações de AIB $\left(0,0 ; 0,1\right.$ e 1,0 $\left.\mathrm{mg} \mathrm{L}^{-1}\right)$, constituindo um fatorial $4 \times 3$, em delineamento inteiramente casualizado para os dois experimentos. Aos 60 dias o melhor desenvolvimento das plantas com raízes normais foi observado quando se utilizou o meio MS na sua concentração normal (100\%) sem AIB. Dessa forma, para a multiplicação e enraizamento in vitro de minirosa, deve ser utilizado o meio $\mathrm{MS}$ com 1,0 $\mathrm{mg} \mathrm{L}^{-1}$ de BAP e o meio MS com $100 \%$ dos sais sem hormônio, respectivamente.
\end{abstract}

Palavras-chave: Micropropagação. Raízes. Rosa chinensis.

\begin{abstract}
The objective of this work was to develop a method for the micro-propagation of the China Rose. Two experiments were conducted using explants from plants grown in vitro. In the first experiment, to test multiplication, the explants were separately seeded onto an MS medium with BAP, CIN and TCT, at concentrations of $0.00,0.01$, $0.10,1.00$ and $10.00 \mathrm{mg} \mathrm{L}^{-1}$ with 15 treatments and 20 explants per treatment. After 80 days it was found that BAP at a concentration of $1.0 \mathrm{mg} \mathrm{L}^{-1}$ favoured the emission of buds and the greatest fresh weight of the explants. For rooting, different formulation concentrations of the macronutrient salts in the MS medium $(25,50,75$ and 100\%) were used, combined with different concentrations of AIB (0.0, 0.1 and $\left.1.0 \mathrm{mg} \mathrm{L}^{-1}\right)$, forming a $4 \times 3$ factorial in a completely randomised design for both experiments. After 60 days, the best development of those plants with normal roots was observed when using the MS medium in its normal concentration (100\%) without AIB. For multiplication and rooting in vitro of the China Rose therefore, MS medium with $1.0 \mathrm{mg} \mathrm{L}^{-1} \mathrm{BAP}$, and MS medium with $100 \%$ of hormone free salts should be used, respectively.
\end{abstract}

Key words: Micropropagation. Roots. Rosa chinensis.

\footnotetext{
*Autor para correspondência

${ }^{1}$ Recebido para publicação em 14/03/2011; aprovado em 12/09/2013

Pesquisa financiada pelo BNB e UFC

${ }^{2}$ Departamento de Fitotecnia, Laboratório de Cultura de Tecidos, Centro de Ciências Agrárias, Universidade Federal do Ceará, Av. Mister Hull, S/N, Bloco 805, Fortaleza-CE, Brasil, 60.356-001, dndiniz@ufc.br

${ }^{3}$ Departamento de Fitotecnia, CCA/Universidade Federal do Ceará, Fortaleza-CE, Brasil, jalac@bol.com.br, aleufc@gmail.com

${ }^{4}$ Mestrando em Agronomia/Fitotecnia, CCA/Universidade Federal do Ceará, Fortaleza-CE, Brasil, vidal.b@bol.com.br
} 


\section{INTRODUÇÃO}

A roseira do gênero Rosa, família Rosácea é uma das flores de corte mais populares no mundo. O gênero apresenta cerca de 200 espécies silvestres e mais de 30 mil variedades, produtos de cruzamentos, sendo que dentre esta gama de variedades, existem inúmeras híbridas que, apesar de serem de clima temperado, passaram por processos de adaptação aos diversos climas, inclusive do Brasil (BOETTCHER, 1991). Neste grande número de variedades encontra-se o grupo das minirosas, que são rosas em miniatura, descendentes de uma espécie natural da China, a Rosa chinensis Jacq, a maioria florescendo continuamente e produzindo flores que vão do branco ao vermelho, passando pelo amarelo, rosa, laranja e púrpura (BITTENCOURT, 2007). Em relação às variedades utilizadas, no cultivo comercial de mini-roseiras, no Brasil não se têm referências sobre sua origem genética, sendo conhecidas pelos nomes populares e diferenciando-se apenas pela coloração das flores (BECKMANN; LUZ; PIVETTA, 2006). Tradicionalmente são multiplicadas por propagação vegetativa através da estaquia, mergulhia e enxertia, o que favorece a disseminação e o acúmulo de patógenos. Além disso, a dependência da época do ano e a baixa taxa de multiplicação limitam a propagação convencional.

De acordo com Pati et al. (2006) a história do cultivo in vitro de roseira data de 1945 quando Nobecourt e Kofler obtiveram calos e raízes a partir de explantes de gemas. Para Dubois et al. (1988) a micropropagação de minirosas resulta em produto de melhor qualidade com maior número de gemas laterais e mais curtas formando plantas mais compactas do que as produzidas por estaquia. E embora muitos e diferentes cultivares de roseiras já tenham sido utilizados na cultura in vitro, os resultados têm sido contraditórios e o uso comercial da técnica tem sido limitado pela baixa taxa de proliferação de gemas axilares, não havendo nenhum protocolo completo que possa ser explorado comercialmente (CARELLI; ECHEVERRIGARAY, 2002; SINGH; SYAMAL, 2001). Dessa forma, uma metodologia eficiente para a produção e o desenvolvimento de plantas de minirosa in vitro pode ser de grande interesse não só para o aumento do número de plantas como também para o desenvolvimento da roseicultura.

No processo de micropropagação, normalmente, reguladores de crescimento como auxinas e citocininas são adicionados ao meio de cultura e sua interação promove respostas morfogenéticas nos tecidos, que dependem do tipo e da concentração utilizada (IRIONDO; MORENO; PÉREZ, 1995). O efeito das citocininas em cultura de tecidos é principalmente em induzir a divisão celular e a diferenciação de gemas adventícias em calos e órgãos. Já as auxinas, segundo Bhojwani e Razdan (1996), são utilizadas em cultura de tecidos para induzir a divisão celular e a diferenciação de raízes. Para o enraizamento, além das auxinas, frequentemente, são feitas alterações na formulação dos sais dos meios de cultivo. Modificações visando otimizar o crescimento in vitro são comumente utilizadas (PASQUAL et al., 2002) e diluições das formulações básicas, geralmente possibilitam melhor enraizamento, conforme observado por Pereira et al. (1999) e Erig, Schuch e Chaves (2004) uma vez que, mesmo na presença de auxinas, altas concentrações dos sais tendem a inibir todas as fases do enraizamento (GRATTAPAGLIA; MACHADO, 1998). Dessa forma, o trabalho teve como objetivo o estabelecimento de um protocolo para a multiplicação e o enraizamento de explantes de minirosa in vitro.

\section{MATERIAL E MÉTODOS}

Nos experimentos foram utilizados explantes retirados de plantas estabelecidas in vitro $\mathrm{e}$ multiplicadas em meio MS (MURASHIGE; SKOOG, 1962) com $0,5 \mathrm{mg} \mathrm{L}^{-1}$ de BAP, até a obtenção de plantas em quantidade suficiente para a realização dos experimentos. Para a multiplicação, segmentos de caule com um ou dois nós e tamanho médio de $10 \mathrm{~mm}$ foram inoculados em meio de cultivo MS com BAP, CIN e Triacontanol (TCT) isoladamente nas concentrações de 0,$00 ; 0,01 ; 0,10 ; 1,00$ e $10,0 \mathrm{mg} \mathrm{L}^{-1}$ com 15 tratamentos e 20 explantes por tratamento em delineamento inteiramente casualizado. Aos 80 dias de cultivo foram avaliados a porcentagem de explantes que emitiram gemas, o número médio de gemas emitidas por explante, a altura média das plantas e o peso seco dos explantes. Foi realizada a análise de variância e a comparação das médias feita pelo teste de Scott-Knott $(\mathrm{P}>0,05)$.

No experimento de enraizamento utilizou-se explantes com tamanho médio de $3 \mathrm{~cm}$ contendo a gema apical e removendo-se os dois pares de folhas mais próximos da base. A seguir foram inoculados em tubo de ensaio, um explante por tubo, contendo $10 \mathrm{~mL}$ do meio MS nas proporções de 25, 50, 75 e $100 \%$ dos sais macronutrientes em todas as combinações possíveis com as concentrações de 0,$0 ; 0,1$ e $1,0 \mathrm{mg} \mathrm{L}^{-1}$ de AIB, resultando em um fatorial $4 \times 3$ num total de 12 tratamentos com 30 explantes por tratamento em delineamento inteiramente casualizado. Nos dois experimentos os explantes foram mantidos em sala de crescimento com temperatura média de $26 \pm 2{ }^{\circ} \mathrm{C}$, fotoperíodo de 16 horas e intensidade luminosa em torno de 2.000 lux. As avaliações da porcentagem de explantes com raízes, número médio de raízes por explante, tamanho médio da maior raiz, altura e peso seco médio das plantas foram feitas aos 60 dias. Após a análise de variância procedeu-se a análise de regressão. 


\section{RESULTADOS E DISCUSSÃO}

\section{Experimento 1}

Aos 80 dias de cultivo, a análise de variância mostrou diferença significativa para todas as variáveis estudadas $(\mathrm{P}>0,05)$. Nesta data todos os explantes haviam emitido gemas com exceção do tratamento testemunha onde $90 \%$ dos explantes apresentavam novas gemas. O número médio de gemas emitidas por explante $(5,2)$ foi significativamente maior no tratamento com 1,0 mg $\mathrm{L}^{-1}$ de BAP (Figura 1A), verificando-se um aumento no número médio de gemas até esta concentração. Com cinetina o número médio de gemas foi significativamente maior com $0,1 \mathrm{mg} \mathrm{L}^{-1}$, sendo esta quantidade quase um terço inferior ao número de gemas observado no tratamento com $1,0 \mathrm{mg} \mathrm{L}^{-1} \mathrm{de}$ BAP. Em explantes de Dioscorea multiflora, Souza et al. (2011), obtiveram melhores resultados na multiplicação, utilizando BAP na concentração de $0,1 \mathrm{mg} \mathrm{L}^{-1}$. De acordo com Iriondo, Moreno e Pérez (1995), o tipo de regulador de crescimento utilizado tem efeito significante no número de gemas emitidas por explante. Furtado et al. (2007) utilizando diferentes citocininas na indução de brotações em explante de gema cotiledonar de amendoim, verificaram que o BAP foi mais eficiente que a cinetina. Da mesma forma, Fior, Rodrigues e Kampf (2000) e Soares et al. (2011), verificaram maior taxa de multiplicação com BAP que com CIN na multiplicação in vitro de Limonium e de mangabeira, respectivamente.

A maior altura média dos explantes foi observada no tratamento com $0,1 \mathrm{mg} \mathrm{L}^{-1}$ de CIN (Figura 1B) embora não tenha apresentado diferença estatística dos demais tratamentos com este regulador. Estes resultados diferem dos obtidos por Iriondo, Moreno e Pérez (1995), que utilizando BAP e CIN em explantes de diferentes espécies de Cistus, verificaram que no meio com CIN as gemas eram significativamente menores que com BAP. Verifica-se também, de modo geral, uma relação inversa entre o número e a altura das gemas, ou seja, quando há a emissão de grande número de gemas, há uma tendência de estas serem um pouco menores, como ocorreu neste experimento, onde o maior número médio de gemas por explante no tratamento com $1,0 \mathrm{mg} \mathrm{L}^{-1}$ de BAP não correspondeu a um maior crescimento em altura das plantas. Provavelmente os nutrientes do meio de cultivo sejam utilizados para o desenvolvimento de maior número de brotações reduzindo sua disponibilidade em quantidade suficiente para o crescimento das mesmas brotações.

O maior acúmulo de peso seco foi observado no tratamento com 1,0 $\mathrm{mg} \mathrm{L}^{-1}$ de BAP (Figura 1C) e tal como ocorreu no número médio de gemas emitidas por explante, houve um aumento de peso seco até a concentração de $1,0 \mathrm{mg} \mathrm{L}^{-1}$, com uma redução quando
Figura 1 - Número médio de gemas emitidas por explante (A), altura das gemas (B) e peso da matéria seca (C) dos explantes de minirosa aos 80 dias de cultivo in vitro em meio MS com diferentes concentrações de BAP, CIN e TCT. Em cada regulador de crescimento, letras iguais para as diferentes concentrações, não diferem entre si pelo teste de Scott-Knott a 5\% de probabilidade
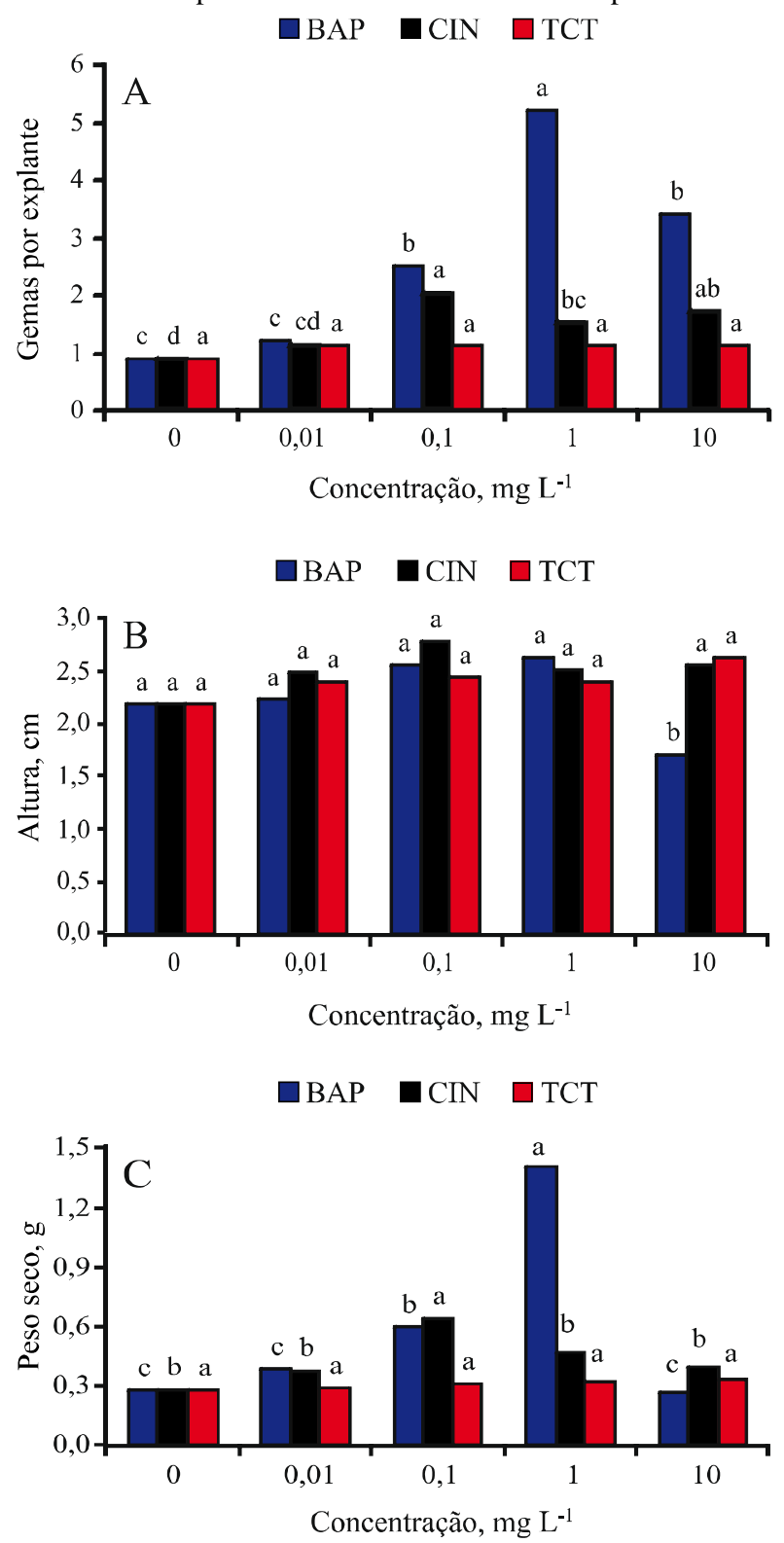

a concentração foi aumentada para $10,0 \mathrm{mg} \mathrm{L}^{-1}$. Na multiplicação in vitro de amoreira-preta, Villa et al. (2005) também verificaram maior peso da matéria seca com $1,0 \mathrm{mg} \mathrm{L}^{-1}$ de BAP.

Com cinetina, o maior peso seco foi verificado com $0,1 \mathrm{mg} \mathrm{L}^{-1}$ havendo um aumento de peso proporcional ao aumento da concentração até este nível, e redução quando a concentração foi aumentada. 
Para o TCT não houve influência das diferentes concentrações utilizadas para as variáveis estudadas, embora seja citado por alguns autores como tendo atividade citocinínica. Segundo Tantos et al. (1999) o TCT é um álcool primário de cadeia longa e sua utilização na multiplicação in vitro de Melissa officinalis L., resultou em um aumento no crescimento de gemas, peso fresco e no teor de clorofila, concluindo que pode ser utilizado como um efetivo regulador de crescimento para a cultura. O mesmo foi observado por Reddy et al. (2002) em Capsicum frutescens e Decalepis hamiltonii onde o uso do TCT resultou em maior produção de gemas axilares.

\section{Experimento 2}

Aos 60 dias, houve diferença significativa para a interação diferentes formulações do meio MS x diferentes concentrações de AIB em todas as variáveis analisadas. Neste período, $85 \%$ dos explantes de minirosa apresentavam raízes. No meio MS com 75 e $100 \%$ da concentração dos sais, na ausência de AIB, houve $100 \%$ de enraizamento (Figura 2). Com $25 \%$ da concentração dos sais MS, verificou-se menor número de explantes enraizados independente da presença ou não de AIB. Nos tratamentos com AIB, verificou-se maior porcentagem de explantes com raízes no meio com $75 \%$ dos sais do meio MS. Derivando as equações obtidas pode-se estimar que $72,5 \%$ e $74 \%$ são as concentrações do meio MS onde seriam alcançados os maiores percentuais de explantes com raízes para 0,1 e $1,0 \mathrm{mg} \mathrm{L}^{-1}$ de AIB, chegando a 88,55 e $94,96 \%$, respectivamente. Também utilizando diferentes concentrações dos sais do meio MS no enraizamento in vitro de explantes de marmeleiro, Erig, Schuch e Chaves (2004), verificaram que 75\% dos sais favoreceram o enraizamento. Porém, estes resultados diferem dos obtidos por Pereira et al. (1999)

Figura 2 - Porcentagem de explantes de minirosa com raízes aos 60 dias de cultivo in vitro em meio MS com diferentes concentrações dos sais e de AIB. ** e* - Significativo a $1 \%$ e $5 \%$ de probabilidade

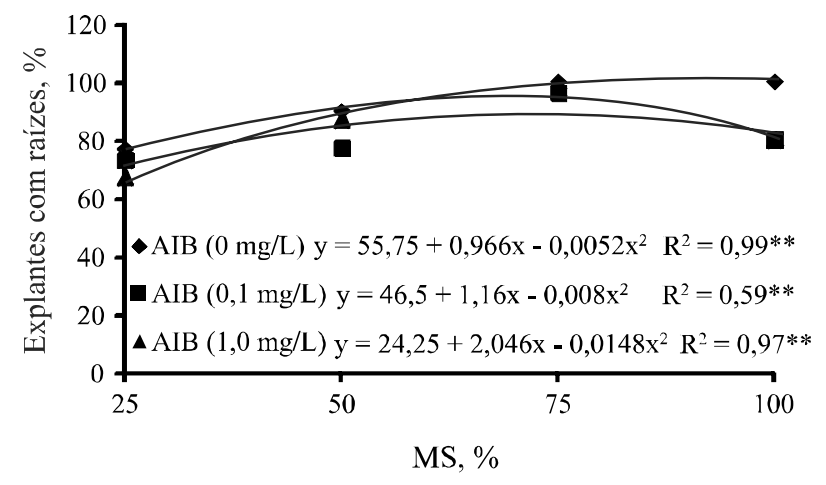

no cultivo in vitro de explantes de morangueiro em que o maior percentual de explantes enraizados foi obtido com a redução da concentração dos sais a metade.

Para o número médio de raízes por explante, tamanho médio das raízes, altura e peso seco dos explantes houve diferença significativa entre as diferentes concentrações de AIB e do meio MS assim com para sua interação.

Na ausência de AIB o número médio de raízes por explante aumentou linearmente com o aumento da concentração do meio MS (Figura 3A). Quando se adicionou AIB o número médio de raízes por explante também aumentou com o aumento da concentração dos sais do meio MS, seguindo uma equação quadrática e com o máximo número médio de raízes em torno de $75 \%$ dos sais (Figura 3A). Com o aumento da concentração de AIB, independentemente da concentração do meio MS, houve um aumento no número médio de raízes por explante e uma redução no tamanho médio das raízes (Figura 3B), verificando-se o maior tamanho no tratamento com 50\% dos sais sem AIB. Pela derivação das equações estima-se que a concentração de $74 \%$ do meio MS proporcionaria o maior número de raízes quando combinada com $0,1 \mathrm{mg} \mathrm{L}^{-1}$ de AIB, chegando a 0,64, enquanto que para $1,0 \mathrm{mg} \mathrm{L}^{-1}$ de AIB o valor máximo do tamanho das raízes foi 0,96 , na concentração de $25 \%$ do meio MS. Porém, nos tratamentos com concentrações mais baixas dos sais, as plantas apresentavam-se menos desenvolvidas e com aspecto amarelado como resultado da diluição excessiva dos macronutrientes que de acordo com Grattapaglia e Machado (1998), pode levar a deficiências minerais na parte aérea enraizada. Melhores resultados quanto ao desenvolvimento da parte aérea e das plântulas foram observados em Zantedeschia aethiopica, e em tangerineira 'Poncã' por Ribeiro et al. (2008) e Pasqual et al. (2002), respectivamente, quando utilizaram o meio MS com $100 \%$ da concentração dos sais.

Apesar da presença de AIB ter favorecido o desenvolvimento de maior número médio de raízes por explante, estas eram duras, curtas, mal formadas e quebradiças, o que normalmente dificulta o processo de aclimatização. E nos tratamentos com 75 e 100\% do meio MS, sem AIB, embora os explantes tenham apresentado menor número médio de raízes, estas eram mais desenvolvidas e com aspecto normal. Estes resultados estão de acordo com os obtidos por Villa et al. (2005) que verificaram melhor desenvolvimento de raízes em brotos de amoreira-preta 'Ebano' na ausência de reguladores. Porém diferem dos resultados observados por Chaves, Schuch e Erig (2006) no enraizamento de Prunus cerasifera com maior número médio de raízes utilizando $0,64 \mathrm{mg} \mathrm{L}^{-1}$ de AIB. Em segmentos nodais de Phyllanthus tenellus, Victório et al. (2010), verificaram 100\% de enraizamento em todas 
Figura 3 - Número médio de raízes por explantes (A), tamanho médio das raízes (B), altura das plantas (C) e peso da matéria seca dos explantes (D) de minirosa aos 60 dias de cultivo in vitro em meio MS com diferentes concentrações dos sais e de AIB. ** e * Significativo a $1 \%$ e $5 \%$ de probabilidade

A

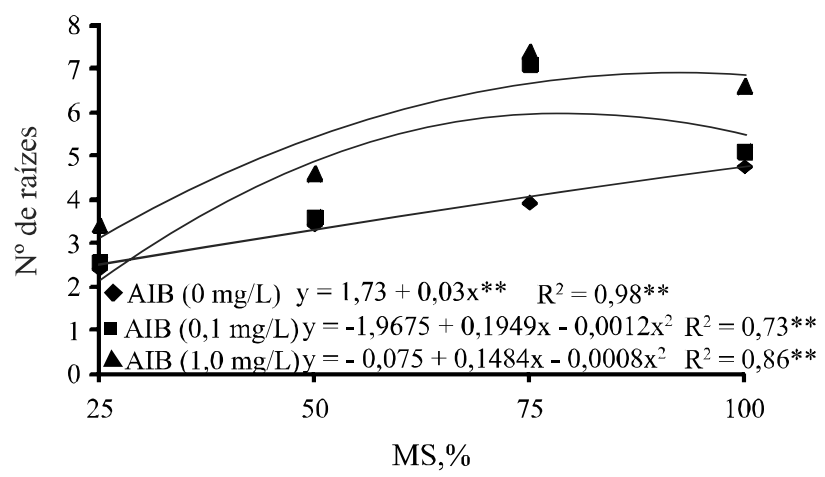

$\mathrm{C}$

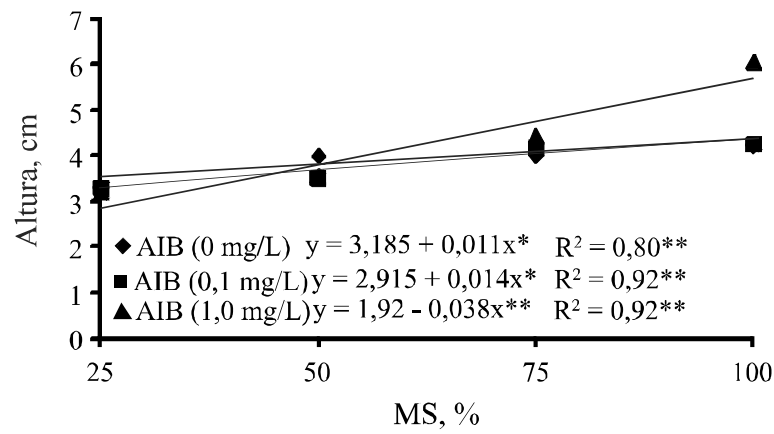

as concentrações de AIB utilizadas. Segundo Quoirin e Lepoivre (1977) as auxinas são utilizadas para estimular o enraizamento do explante inicial e a manutenção de um caule único com dominância apical. Para Grattapaglia e Machado (1998), as auxinas estimulam o enraizamento, porém concentrações excessivas podem induzir um superbrotamento de raízes, conforme foi observado por Diniz et al. (2008) quando utilizaram concentrações crescentes de AIB no enraizamento in vitro de explantes de Spathiphyllum wallisi.

Quanto à altura e o peso seco médio das plantas, maiores concentrações dos sais do meio MS e de AIB favoreceram o crescimento, seguindo uma tendência linear e verificando-se maior altura média $(6,04 \mathrm{~cm})$ e maior peso seco $(1,25 \mathrm{~g})$ no tratamento com $100 \%$ dos sais e $1,0 \mathrm{mg} \mathrm{L}^{-1}$ de AIB (Figura 3C e 3D). Porém neste tratamento as plantas apresentavam-se hiperhídricas, mal formadas com aspecto anormal.

No tratamento com $100 \%$ dos sais sem AIB, as plantas, mesmo não sendo as de maior altura, eram verdes
B

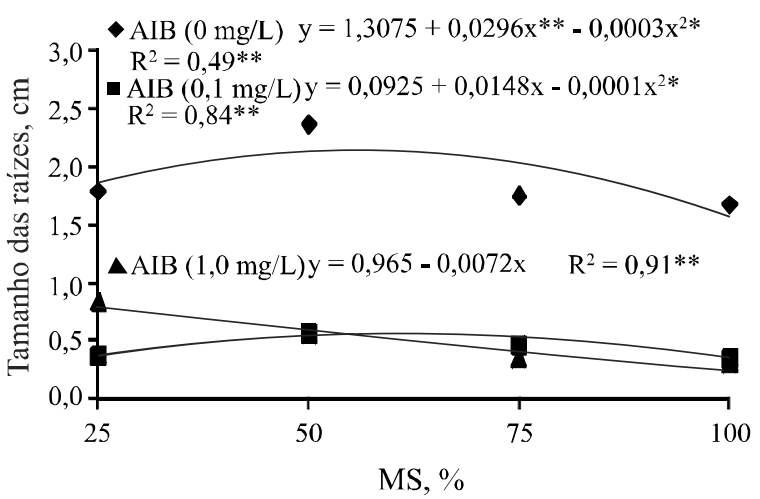

$\mathrm{D}$

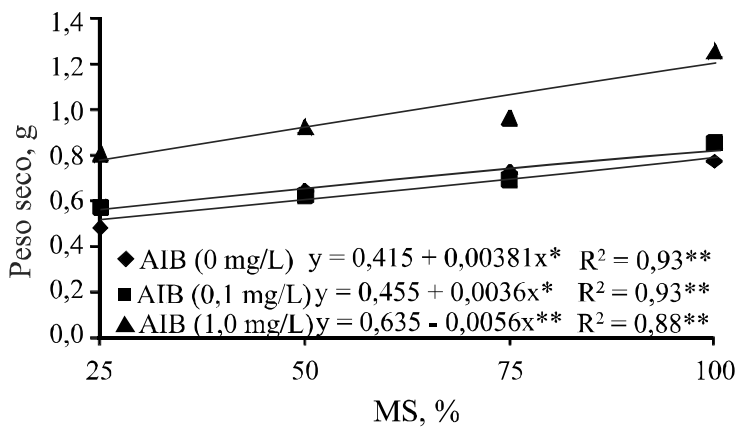

e bem desenvolvidas com número satisfatório de raízes, bom tamanho e crescimento normal, mostrando ser este o tratamento mais adequado para a obtenção de plantas com melhores condições de serem aclimatizadas.

\section{CONCLUSÕES}

1.Para a multiplicação in vitro de minirosa, a citocinina BAP na concentração de $1,0 \mathrm{mg} \mathrm{L}^{-1}$ favorece a emissão de maior número médio de gemas assim como, o maior peso seco dos explantes;

2. O triacontanol nas concentrações testadas não apresenta atividade citocinínica em explantes de minirosa;

3. No enraizamento, o meio MS com $100 \%$ dos sais, sem AIB, favorece o desenvolvimento de plantas com raízes normais, em boa quantidade e com maior tamanho, sendo que o AIB, mesmo em pequenas concentrações, induz a formação de raízes curtas, grossas e de má qualidade. 


\section{AGRADECIMENTOS}

Ao Banco do Nordeste do Brasil pelo apoio financeiro.

\section{REFERÊNCIAS}

BECKMANN, M. Z.; LUZ, F. J. de F.; PIVETTA, K. F. L. Marcador fAFLP na identificação da diversidade genética de mini-roseiras. Revista de Biologia e Ciências da Terra, v. 6 , n. 1, p. 139-144, 2006.

BHOJWANI, S. S.; RAZDAN, M. K. Tissue cultura media. In: Plant tissue culture: theory and pratice, a revised edition. Amsterdã: Elsevier, 1996. p. 39-62.

BITTENCOURT, R. O começo de um jardim. [s.l.: s.n.], 2007. Disponível em: <http://solangecassio.multiply.com/journal/ item/13>. Acesso em: 8 out. 2012 .

BOETTCHER, A. Sítios e jardins: rosas. São Paulo: Editora Europa, 1991. 87 p.

CARELLI, B. P.; ECHEVERRIGARAY, S. An improved system for the in vitro propagation of rose cultivars. Scientia Horticulturae, v. 92, n. 1, p. 69-74, 2002.

CHAVES, A. da C.; SCHUCH, M.W.; ERIG, A. C. Efeito do meio de cultura e concentrações de auxinas no enraizamento in vitro de Prunus cerasifera cv. MR. S. 1/8. Plant Cell Culture \& Micropropagation, v. 2, n. 1, p. 43-47, 2006.

DINIZ, J. D. N. et al. Protocolo para desinfestação, multiplicação e enraizamento in vitro de Spathiphyllum wallisi. Revista Ciência Agronômica, v. 39, n. 1, p. 107-113, 2008.

DUBOIS, L. A. M. et al. Comparison of the growth and development of dwarf rose cultivars propagated in vitro and in vivo by softwood cuttings. Scientia Horticulturae, v. 35, n.3/4, p. 293-299, 1988.

ERIG, A. C.; SCHUCH, M. W.; CHAVES, A. da C. Enraizamento in vitro e aclimatização de mudas de marmeleiro Cvs. MC e Adams, utilizadas como porta-enxerto para a pereira. Scientia Agraria, v. 5, n. 1/2, p. 61-68, 2004.

FIOR, C. S.; RODRIGUES, L. R.; KÄMPF, A. N. Propagação in vitro de Limonium latifolium Kuntze (Plumbaginaceae). Ciência Rural, v. 30, n. 4, p. 575-580, 2000.

FURTADO, C. M. et al. Comparação da freqüência de regeneração in vitro do amendoim (Arachis hipogaea), utilizando diferentes citocininas. Revista de Biologia e Ciências da Terra, v. 7, n. 1, p. 51-58, 2007.

GRATTAPAGLIA, D.; MACHADO, M. A. Micropropagação. In: TORRES, A. C.; CALDAS, L. S.; BUSO, J. A. Cultura de tecidos e transformação genética de plantas. 1. ed. Brasília: SPI/Embrapa - CNPH, 1998. p. 183-230. v. 1.

IRIONDO, J. M.; MORENO, C.; PÉREZ, C. Micropropagation of six rockrose (Cistus) species. HortScience, v. 30, n. 5, p. 1080-1081, 1995.

MURASHIGE, T.; SKOOG, F. A revised medium for rapid growth and bioassays with tobacco tissue cultures. Physiologia Plantarum, v. 15, n. 3, p. 473-497, 1962.

PASQUAL, M. et al. Cultivo in vitro de embriões imaturos de tangerineira 'poncã': concentrações do meio MS e da sacarose. Revista Ceres, v. 49, n. 282, p. 181-189, 2002.

PATI, P. K. et al. In vitro propagation of rose - a review. Biotechnology Advances, v. 24, n.1, p. 94-114, 2006.

PEREIRA, J. E. S. et al. Enraizamento in vitro do morangueiro (Fragaria $x$ ananassa Duchesne) em diferentes concentrações do meio MS. Ciência Rural, v. 29, n. 1, p. 17-20, 1999.

QUOIRIN, M.; LEPOIVRE, P. Etude de milieux adaptés aux cultures in vitro de Prunus. Acta Horticulturae, v. 78, p. 437-442, 1977.

REDDY, B. O.; GIRIDHAR, P.; RAVISHANGAR, G. A. The effect of triacontanol on micropropagation of Capsicum frutescens and Decalepsis hamiltonii W \& A. Plant Cell, Tissue and Organ Culture, v. 71, p. 253-258, 2002.

RIBEIRO, M. N. O. et al. Diferentes concentrações de sais do meio MS e de sacarose na multiplicação in vitro de Zantedeschia aethiopica L. Spreng (copo-de-leite). Revista Ciência Agronômica, v. 39, n. 1, p. 101-106, 2008.

SINGH, S. K.; SYAMAL, M. M. A short pre-culture soak in thidiazuron or forchlorfenuron improves axillary shoot proliferation in rose micropropagation. Scientia Horticulturae, v. 91, n.1/2, p. 169-177, 2001.

SOARES, F. P. et al. Taxa de multiplicação e efeito residual de diferentes fontes de citocinina no cultivo in vitro de Hancornia speciosa Gomes. Ciência e Agrotecnologia, v. 35, n. 1, p. 152-157, 2011.

SOUZA, A. V. de. et al. Micropropagação de Dioscorea multiflora Grised. Ciência e Agrotecnologia, v. 35, n. 1, p. 92-98, 2011.

TANTOS, A. et al. The effect of triacontanol on micropropagation of balm, Melissa officinalis L. Plant Cell Reports, v. 19, p. 88-91, 1999.

VICTÓRIO, C. P. et al. Standardized production of Phyllanthus tenellus Roxb. by plant tissue culture. Revista Ciência Agronômica, v. 41, n. 2, p. 272-278, 2010.

VILLA, F. et al. Multiplicação in vitro da amoreira-preta 'Ébano' em diferentes concentrações de meio MS e BAP. Ciência e Agrotecnologia, v. 29, n. 3, p. 582-589, 2005. 